\title{
Rekomendasi Penerima Bantuan Siswa Miskin (BSM) dengan Metode Simple Additive Weighting (SAW). Studi Kasus : SMP N 1 Lintongnihuta
}

\author{
Denni M Rajagukguk \\ Universitas Imelda Medan, Jl. Bilal Ujung No.24,52, Pulo Brayan Darat I, Medan Timur, Indonesia \\ rajdenni@yahoo.co.id
}

\begin{abstract}
Abstrak-Program BSM adalah Program Nasional yang bertujuan untuk menghilangkan halangan siswa miskin berpartisipasi untuk bersekolah dengan membantu siswa miskin memperoleh akses pelayanan pendidikan yang layak, mencegah putus sekolah, menarik siswa miskin untuk kembali bersekolah, membantu siswa memenuhi kebutuhan dalam kegiatan pembelajaran, mendukung program Wajib Belajar Pendidikan Dasar Sembilan Tahun (bahkan hingga tingkat menengah atas), serta membantu kelancaran program sekolah. Melalui Program BSM ini diharapkan anak usia sekolah dari rumah-tangga/keluarga miskin dapat terus bersekolah, tidak putus sekolah, dan di masa depan diharapkan mereka dapat memutus rantai kemiskinan yang saat ini dialami orangtuanya. Program BSM juga mendukung komitmen pemerintah untuk meningkatkan angka partisipasi pendidikan di Kabupaten/Kota miskin dan terpencil serta pada kelompok marjinal. Pada hakekatnya metode simple additive weighting (SAW) sering juga dikenal dengan istilah metode penjumlahan terbobot. Konsep dasar metode simple additive weighting (SAW) adalah mencari penjumlahan terbobot dari rating kinerja pada setiap alternatif pada semua atribut. Metode simple additive weighting $(S A W)$ membutuhkan proses normalisasi matriks keputusan.
\end{abstract}

Kata kunci: SPK, Metode SAW.

Abstract-The BSM Program is a National Program that aims to remove barriers to poor students from participating in school by helping poor students to get access to appropriate education services, preventing dropouts, attracting poor students to return to school, helping students meet needs in learning activities, supporting Mandatory programs Learning Nine-year Basic Education (even to the senior secondary level), and helping the smooth running of school programs. Through this BSM program it is hoped that school-age children from poor households / families can continue to go to school, not dropping out of school, and in the future they are expected to break the poverty chain currently experienced by their parents. The BSM program also supports the government's commitment to increase education participation rates in poor and remote regencies / cities and marginalized groups. In essence the simple additive weighting (SAW) method is often also known as the weighted sum method. The basic concept of the simple additive weighting (SAW) method is to find the weighted sum of the performance ratings for each alternative on all attributes. The simple additive weighting (SAW) method requires the decision matrix normalization process.

Keywords: SPK, SAW Method.

\section{PENDAHULUAN}

Bantuan Siswa Miskin (BSM) adalah bantuan dari pemerintah berupa sejumlah uang tunai yang diberikan secara langsung kepada siswa sesuai kriteria yang telah ditetapkan. Dalam upaya pemerataan kesempatan memperoleh pendidikan dan mutu pendidikan [1]. Dan menekan angka putus sekolah pemerintah memperluas akses pendidikan yang lebih bermutu dan merata dengan memberikan perhatian yang lebih besar kepada penduduk miskin. Perhatian itu berupa pemberian Bantuan Siswa Miskin (BSM). Bantuan ini diberikan Pemerintah dalam rangka kompensasi atas kenaikan harga BBM (Bahan Bakar Minyak). Pemerintah Indonesia meyakini tindakan ini adalah penting untuk menyelamatkan fiskal negara, meskipun pemerintah juga meyakini bahwa ini adalah keputusan yang sulit bagi pemerintah.

Seleksi penerimaan BSM (Bantuan Siswa Miskin) merupakan tipe masalah semi terstruktur artinya proses ini bukan agenda rutin suatu sekolah melainkan kejadian insidental. Panitia penerimaan BSM (Bantuan Siswa Miskin) dalam pengambilan keputusan sebelumnya menggunakan sistem manual. Dalam menentukan keputusan calon penerima BSM (Bantuan Siswa Miskin) panitia harus mengumpulkan data seleksi calon penerima BSM (Bantuan Siswa Miskin) dari data siswa yang berasal dari keluarga sederhana sampai kurang mampu[2].

Hal ini membuat panitia penerimaan BSM (Bantuan Siswa Miskin) sedikit kesulitan dalam pengambilan keputusan. Mengingat permasalahan yang dihadapi, maka aplikasi ini dibuat sebagai salah satu sarana informasi untuk membantu panitia penerima BSM (Bantuan Siswa Miskin) dalam menentukan apakah calon siswa dapat menerima BSM (Bantuan Siswa Miskin).

Sistem Pendukung Keputusan (SPK) / Decision Support System (DSS) merupakan sistem informasi interaktif yang menyediakan informasi, pemodelan, dan pemanipulasian data. Sistem ini digunakan untuk membantu pengambilan keputusan dalam situasi yang semiterstruktur dan situasi yang tidak terstruktur, di mana tak seorangpun tahu secara pasti bagaimana keputusan seharusnya dibuat [3]. Decision Support System (DSS) biasanya dibangun untuk mendukung solusi atas suatu masalah atau untuk mengevaluasi suatu peluang. Decision Support Sistem (DSS) yang seperti itu disebut aplikasi Decision Support System (DSS). Aplikasi Decision Support Sysstem (DSS) digunakan dalam pengambilan keputusan [4]. Aplikasi Decision Support System (DSS) menggunakan CBIS (Computer Based Information Systems) yang fleksibel, 
interaktif, dan dapat diadaptasi, yang dikembangkan untuk mendukung solusi atas masalah manajemen spesifik yang tidak terstruktur. Aplikasi Decision Support System (DSS) menggunakan data, memberikan antarmuka pengguna yang mudah, dan dapat menggabungkan pemikiran pengambilan keputusan. Dari sisi konteks, pada dasarnya sebuah Sistem Pendukung Keputusan mempelajari suatu sistem akan lebih mengenal apabila mengetahui terlebih dahulu apa itu sistem. Lebih lanjut pengertian tentang sistem pertama kali dapat diperoleh dari defenisinya. Dengan demikian defenisi ini akan mempunyai peranan penting didalam pendekatan untuk mempelajari suatu sistem. Pendekatan sistem yang merupakan kumpulan dari elemenelemen atau komponen-komponen atau subsistem-subsistem merupakan defenisi yang luas[5]. Defenisi ini lebih banyak diterima, karena kenyataan suatu sistem dapat terdiri dari beberapa subsistem atau sistem bagian lainnya.

Metode Simple Additive Weighting (SAW) sering juga dikenal istilah metode penjumlahan terbobot. Konsep dasar metode SAW adalah mencari penjumlahan terbobot dari rating kinerja pada setiap alternatif pada semua atribut. Metode SAW membutuhkan proses normalisasi matriks keputusan (X) ke suatu skala yang dapat diperbandingkan dengan semua rating alternatif yang ada[5]. Metode ini merupakan metode yang paling terkenal dan paling banyak digunakan dalam menghadapi situasi Multiple Attribute Decision Making (MADM) [6]. MADM itu sendiri merupakan suatu metode yang digunakan untuk mencari alternatif optimal dari sejumlah alternatif dengan kriteria tertentu.

\section{METODE PENELITIAN}

Metode penelitian yang digunakan dalam melakukan pencarian siswa penenrima BSM pada penelitian ini dengan tahap-tahap sebagai berikut [7]:

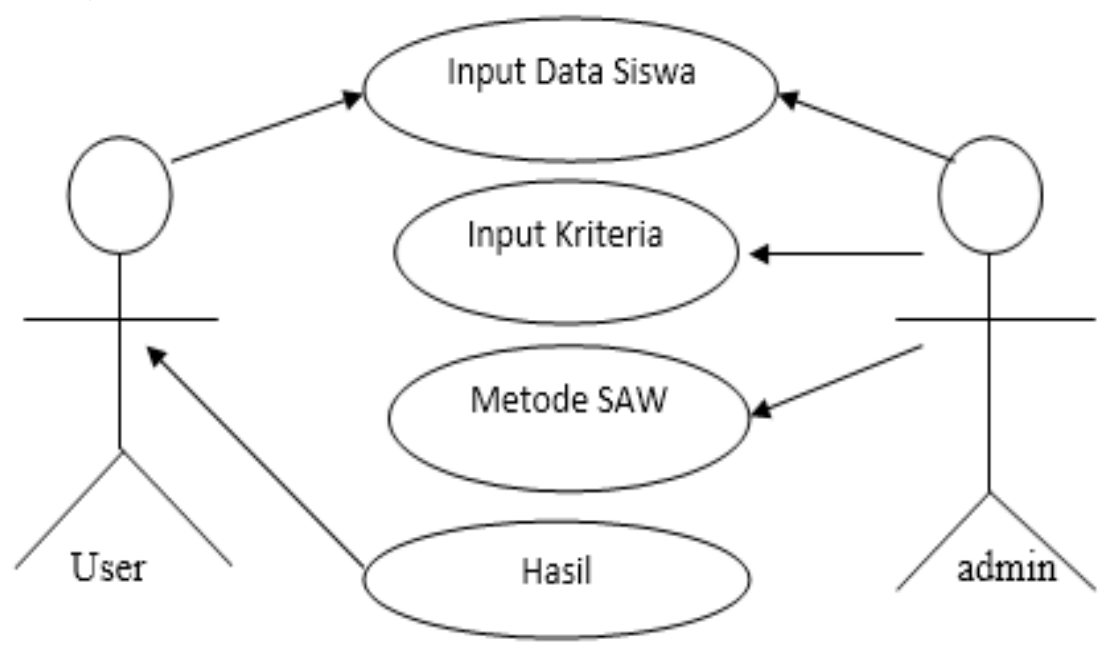

Gambar 1. Metode Penelitian

Metode SAW ini mengharuskan pembuat keputusan menentukan bobot bagi setiap atribut. Skor total untuk alternatif diperoleh dengan menjumlahkan seluruh hasil perkalian antara rating (yang dapat dibandingkan lintas atribut) dan bobot tiap atribut. Rating tiap atribut haruslah bebas dimensi dalam arti telah melewati proses normalisasi matriks sebelumnya.

Langkah-langkah penyelesaian dengan metode SAW yaitu[8]:

1. Menentukan kriteria-kriteria yang akan dijadikan acuan dalam pengambilan keputusan, yaitu Ci.

2. Menentukan rating kecocokan setiap alternatif pada setiap kriteria.

3. Membuat matriks keputusan berdasarkan kriteriac(Ci), kemudian melakukan normalisasi matriks berdasarkan persamaan yang disesuaikan dengan jenis atribut (atribut keuntungan ataupun atribut biaya) sehingga diperoleh matriks ternormalisasi $\mathrm{R}$.

4. Hasil akhir diperoleh dari proses perankingan yaitu penjumlahan dari perkalian matriks ternormalisasi $\mathrm{R}$ dengan vektor bobot sehingga diperoleh nilai terbesar yang dipilih sebagai alternatif terbaik (Ai)

Metode SAW membutuhkan proses normalisasi matriks keputusan (X) ke suatu skala yang dapat diperbandingkan dengan semua rating alternatif yang ada. Formula untuk melakukan normalisasi tersebut adalah sebagai berikut : 


$$
\mathbf{r}_{i j}= \begin{cases}\frac{x_{i j}}{\operatorname{Max}_{i}} & \text { jika jadalah atribut keuntungan (benefit) } \\ \frac{\operatorname{Min}_{i j}}{x_{i j}} & \text { jika jadalah atribut biaya (cost) }\end{cases}
$$

dengan rij adalah rating kinerja ternormalisasi dari alternatif $\mathrm{Ai}$ pada atribut $\mathrm{Cj} ; \mathrm{i}=1,2, \ldots, \mathrm{m}$ dan $\mathrm{j}=1,2, \ldots, \mathrm{n}$.

- Nilai preferensi untuk setiap alternatif (Vi) diberikan sebagai:

$$
\mathbf{V}_{\mathrm{i}}=\sum_{\mathrm{j}=1}^{\mathrm{n}} \mathbf{w}_{\mathrm{j}} \mathbf{r}_{\mathrm{ij}}
$$

- Nilai Vi yang lebih besar mengindikasikan bahwa alternatif Ai lebih terpilih.

\subsection{Data yang digunakan}

\section{HASIL DAN PEMBAHASAN}

Kriteria yang digunakan untuk Pendukung keputusan ini adalah Semester (S), Penghasilan orang Tua (POT), Rata-Rata Nilai Semester (RNS), Jumlah Tanggungan Orang Tua (JTO), Nilai Ekstra (NE), Prestasi $(\mathrm{P})$.

Tabel 1. Tabel Kriteria

\begin{tabular}{|l|l|l|l|l|l|l|l|}
\hline \multirow{2}{*}{ NO } & \multirow{2}{*}{ NAMA } & \multicolumn{5}{|c|}{ KRITERIA } \\
\cline { 3 - 9 } & & S & POT & RNS & $\begin{array}{l}\text { JT } \\
\text { O }\end{array}$ & NE & P \\
\hline 1 & Raden Josua Sihombing & 3 & $2 \mathrm{jt}$ & 70 & 3 & $\mathrm{~B}$ & 1 \\
\hline 2 & Nikson Silaban & 3 & $1,2 \mathrm{jt}$ & 75 & 2 & $\mathrm{C}$ & 2 \\
\hline 3 & Abidin Siregar & 3 & $1 \mathrm{jt}$ & 70 & 2 & $\mathrm{~B}$ & 3 \\
\hline 4 & Zulkifli Lumban Toruan & 5 & 1,5 & 85 & 3 & $\mathrm{C}$ & 6 \\
\hline 5 & Marudut Sinaga & 5 & $2 \mathrm{jt}$ & 80 & 5 & $\mathrm{~B}$ & 5 \\
\hline 6 & Martina Manullang & 5 & $2,5 \mathrm{jt}$ & 75 & 1 & $\mathrm{~B}$ & 4 \\
\hline 7 & Lestari Aritonang & 3 & $1,2 \mathrm{jt}$ & 80 & 4 & $\mathrm{~B}$ & 6 \\
\hline
\end{tabular}

Dengan ranking kecocokan setiap alternatif pada setiap kriteria, dinilai dengan 1 sampai 5, yaitu:

$1=$ sangat buruk

$2=$ buruk

$3=$ cukup

$4=$ baik

$5=$ sangat baik.

Kriteria yang menjadi bahan pertimbangan panitia penyeleksi pemberian bantuan seperti yang ditunjukan pada tabel 1 Pengambil keputusan memberikan bobot preferensi dengan nilai $\mathrm{W}=5,4,3,3,2$.

Adapun yang menjadi pembobotan setiap kriteria adalah sebagai berikut :

Tabel 2. Tabel Pembobotan

\begin{tabular}{|l|c|}
\hline Pembobotan & Nilai \\
\hline Sangat rendah & 1 \\
\hline Rendah & 2 \\
\hline Cukup & 3 \\
\hline Tinggi & 4 \\
\hline Sangat tinggi & 5 \\
\hline
\end{tabular}


Tabel 3. Tabel Pembobotan Rata - Rata Nilai Semester (RNS)

\begin{tabular}{|c|l|l|}
\hline $\begin{array}{l}\text { Rata }- \text { Rata Nilai } \\
\text { Semester }\end{array}$ & Pembobotan & Nilai \\
\hline $85-99$ & Sangat tinggi & 5 \\
\hline $80-84$ & Tinggi & 4 \\
\hline $75-79$ & Cukup & 3 \\
\hline $70-74$ & Rendah & 2 \\
\hline $50-70$ & Sangat Rendah & 1 \\
\hline
\end{tabular}

Tabel 4. Tabel Pembobotan Semester (S)

\begin{tabular}{|c|c|c|}
\hline Semester & Pembobotan & Nilai \\
\hline $5-6$ & $\begin{array}{c}\text { Sangat } \\
\text { Tinggi }\end{array}$ & 5 \\
\hline 4 & Tinggi & 4 \\
\hline 3 & Cukup & 3 \\
\hline 2 & Rendah & 2 \\
\hline
\end{tabular}

Tabel 5. Pembobotan Jumlah Tanggungan Orang Tua (JTO)

\begin{tabular}{|c|c|c|}
\hline $\begin{array}{c}\text { Jumlah } \\
\text { Tanggungan }\end{array}$ & Pembobotan & Nilai \\
\hline$>5$ & Sangat tinggi & 5 \\
\hline 4 & Tinggi & 4 \\
\hline 3 & Cukup & 3 \\
\hline 2 & Rendah & 2 \\
\hline 1 & $\begin{array}{c}\text { Sangat } \\
\text { Rendah }\end{array}$ & 1 \\
\hline
\end{tabular}

Tabel 6. Pembobotan Penghasilan Orang Tua (POT)

\begin{tabular}{|c|c|c|}
\hline POT & Pembobotan & Nilai \\
\hline$<1 \mathrm{jt}$ & Sangat Rendah & 1 \\
\hline $1 \mathrm{jt}-1.5 \mathrm{jt}$ & Rendah & 2 \\
\hline $1.6 \mathrm{jt}-2 \mathrm{jt}$ & Cukup & 3 \\
\hline $2.1 \mathrm{jt}-3 \mathrm{jt}$ & Tinggi & 4 \\
\hline $3.1 \mathrm{jt}-4 \mathrm{jt}$ & Sangat Tinggi & 5 \\
\hline
\end{tabular}

Tabel 7. Tabel Pembobotan Nilai Ekstra (NE)

\begin{tabular}{|c|c|c|}
\hline Kriteria Nilai Ekstra & Pembobotan & Nilai \\
\hline $85-99$ & Sangat tinggi & 5 \\
\hline $80-84$ & Tinggi & 4 \\
\hline $75-79$ & Cukup & 3 \\
\hline $70-74$ & Cukup & 2 \\
\hline $50-70$ & Rendah & 1 \\
\hline
\end{tabular}

Tabel 8. Tabel Pembobotan Prestasi (P)

\begin{tabular}{|c|c|c|}
\hline Kriteria Prestasi & Pembobotan & Nilai \\
\hline $1-3$ & Sangat tinggi & 5 \\
\hline $4-5$ & Tinggi & 4 \\
\hline $6-7$ & Cukup & 3 \\
\hline $8-9$ & Cukup & 2 \\
\hline 10 & Rendah & 1 \\
\hline
\end{tabular}


Dalam penentuan rating kecocokan maka nilai dari masing-masing kriteria di atas dimasukkan ke dalam tabel rating kecocokan yang telah disesuaikan dengan nilai dari tabel kriteria. Maka tabel rating kecocokan dapat dilihat seperti tabel berikut:

Tabel 9. Rating Kecocokan dari Setiap Kriteria

\begin{tabular}{|l|c|c|c|c|c|c|}
\hline \multirow{2}{*}{\multicolumn{1}{c|}{ NAMA }} & \multicolumn{7}{c|}{ Kriteria } \\
\cline { 2 - 7 } & S & POT & RNS & JTO & NE & P \\
\hline Raden Josua Sihombing & 3 & 3 & 2 & 3 & 4 & 5 \\
\hline Nikson Silaban & 3 & 2 & 3 & 2 & 3 & 5 \\
\hline Abidin Siregar & 3 & 2 & 2 & 2 & 4 & 5 \\
\hline Zulkifli Lumban Toruan & 5 & 2 & 5 & 3 & 3 & 3 \\
\hline Marudut Sinaga & 5 & 3 & 4 & 5 & 4 & 4 \\
\hline Martina Manullang & 5 & 4 & 3 & 1 & 4 & 4 \\
\hline Lestari Aritonang & 3 & 2 & 4 & 4 & 4 & 3 \\
\hline
\end{tabular}

Dalam menentukan nilai transformasi ke dalam matriks X merupakan nilai dari hasil tabel rating kecocokan di atas dibuat menjadi bentuk matriks.

$$
X=\left(\begin{array}{llllll}
3 & 3 & 2 & 3 & 4 & 5 \\
3 & 2 & 3 & 2 & 3 & 5 \\
3 & 2 & 2 & 2 & 4 & 5 \\
5 & 2 & 5 & 3 & 3 & 3 \\
5 & 3 & 4 & 5 & 4 & 4 \\
5 & 4 & 3 & 1 & 4 & 4 \\
3 & 2 & 4 & 4 & 4 & 3
\end{array}\right)
$$

Untuk menentukan bobot dari kriteria siswa dibentuk pada tabel 10

Tabel 10. Bobot untuk Kriteria

\begin{tabular}{|l|l|c|}
\hline \multicolumn{1}{|c|}{ Kriteria } & \multicolumn{1}{c|}{ Bobot } & Nilai \\
\hline (C1) & Tinggi & 4 \\
\hline (C2) POT & Tinggi & 4 \\
\hline (C3) RNS & Tinggi & 4 \\
\hline (C4) JTO & Cukup & 3 \\
\hline (C5) NE & Sedang & 2 \\
\hline (C6) P & Tinggi & 4 \\
\hline
\end{tabular}

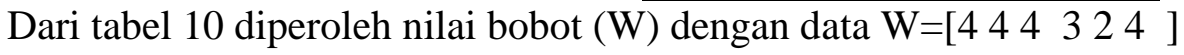

Untuk perhitungan matriks R membutuhkan penggolongan Kriteria ke dalam nilai benefit atau cost, dimana yang menjadi atribut dari keuntungan adalah benefit, sedangkan untuk cost merupakan atribut dari biaya.

Tabel 11. Penentuan Benefit atau Cost

\begin{tabular}{|l|l|l|}
\hline Kriteria & Cost & Benefit \\
\hline Semester & - & $\sqrt{ }$ \\
\hline POT & $\sqrt{ }$ & \\
\hline RNS & - & $\sqrt{ }$ \\
\hline JTO & - & $\sqrt{ }$ \\
\hline NE & - & $\sqrt{ }$ \\
\hline P & - & $\sqrt{ }$ \\
\hline
\end{tabular}

Dalam menormalisasi matriks X ke matriks $\mathrm{R}$, maka yang harus dilakukan adalah menentukan nilai $\mathrm{R}$ dari masing-masing kriteria.

a. Untuk Semester termasuk ke dalam atribut keuntungan (benefit), karena semakin besar nilai maka semakin baik.

$\mathrm{R}_{1,1}=\frac{3}{\max \{3335553\}}=\frac{3}{5}=0.6$ 


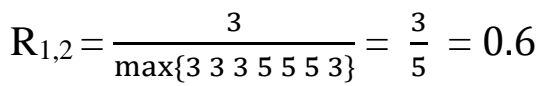

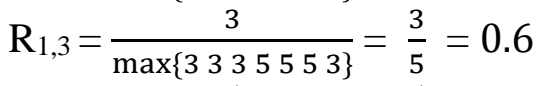

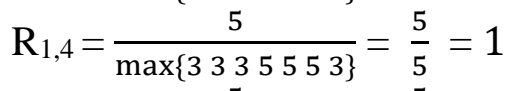

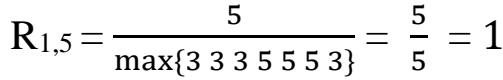

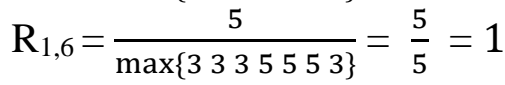

$$
\begin{aligned}
& \mathrm{R}_{1,7}=\frac{3}{\max \{3335553\}}=\frac{3}{5}=0.6
\end{aligned}
$$

b. Untuk Penghasilan Orang Tua (POT) termasuk ke dalam atribut Cost, karena semakin kecil nilai maka semakin baik.

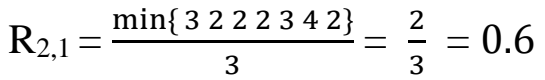

$$
\begin{aligned}
& \mathrm{R}_{2,2}=\frac{\min \left\{\begin{array}{llllll}
3 & 2 & 2 & 2 & 3 & 4
\end{array}\right\}}{2}=\frac{2}{2}=1 \\
& \mathrm{R}_{2,3}=\frac{\min \left\{\begin{array}{llllll}
3 & 2 & 2 & 2 & 3 & 4
\end{array}\right\}}{2}=\frac{2}{2}=1 \\
& \mathrm{R}_{2,4}=\frac{\min \left\{\begin{array}{llllll}
3 & 2 & 2 & 2 & 3 & 4
\end{array}\right\}}{2}=\frac{2}{2}=1
\end{aligned}
$$

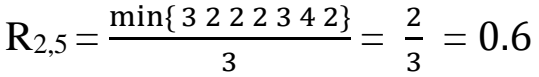

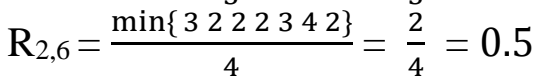

$$
\begin{aligned}
& \mathrm{R}_{2,7}=\frac{\min \left\{\begin{array}{llllll}
3 & 2 & 2 & 2 & 3 & 4
\end{array}\right\}}{2}=\frac{2}{2}=1
\end{aligned}
$$

c. Untuk RNS termasuk ke dalam atribut keuntungan (benefit), karena semakin besar nilai maka semakin baik.

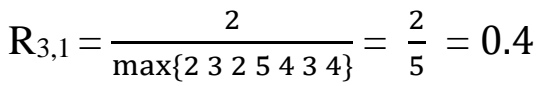

$$
\begin{aligned}
& \mathrm{R}_{3,2}=\frac{3}{\max \{2325434\}}=\frac{3}{5}=0.6 \\
& \mathrm{R}_{3,3}=\frac{2}{\max \{2325434\}}=\frac{2}{5}=0.4
\end{aligned}
$$

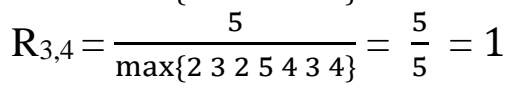

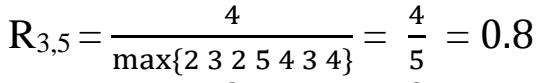

$$
\begin{aligned}
& \mathrm{R}_{3,6}=\frac{3}{\max \{23255434\}}=\frac{3}{5}=0.6
\end{aligned}
$$

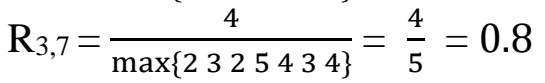

d. Untuk Jumlah Tanggungan termasuk ke dalam atribut keuntungan (benefit), karena semakin besar nilai maka semakin baik.

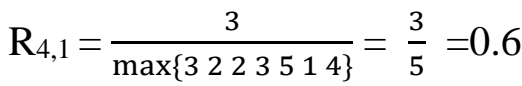

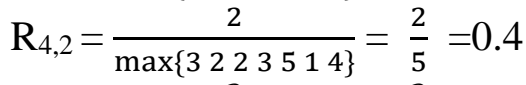

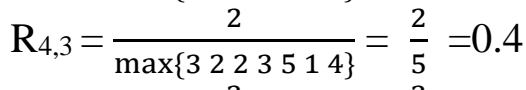

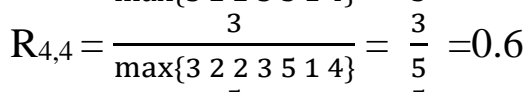

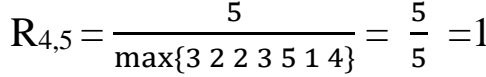

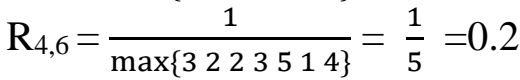

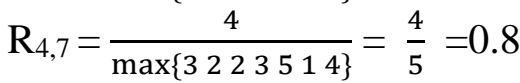

e. Untuk Nilai Ekstra termasuk ke dalam atribut keuntungan (benefit), karena semakin besar nilai maka semakin baik.

$\mathrm{R}_{5,1}=\frac{.4}{\max \{4343444\}}=\frac{4}{4}=1$ 


$$
\begin{aligned}
& \mathrm{R}_{5,2}=\frac{.3}{\max \{4343444\}}=\frac{3}{4}=0.75 \\
& \mathrm{R}_{5,3}=\frac{.4}{\max \{4343444\}}=\frac{4}{4}=1 \\
& \mathrm{R}_{5,4}=\frac{.3}{\max \{4343444\}}=\frac{3}{4}=0.75 \\
& \mathrm{R}_{5,5}=\frac{.4}{\max \{4343444\}}=\frac{4}{4}=1 \\
& \mathrm{R}_{5,6}=\frac{.4}{\max \{4343444\}}=\frac{4}{4}=1 \\
& \mathrm{R}_{5,7}=\frac{.4}{\max \{4343444\}}=\frac{4}{4}=1
\end{aligned}
$$

f. Untuk Prestasi termasuk ke dalam atribut keuntungan (benefit), karena semakin besar nilai maka semakin baik.

$$
\begin{aligned}
& \mathrm{R}_{6,1}=\frac{5}{\max \{5553443\}}=\frac{5}{5}=1 \\
& \mathrm{R}_{6,2}=\frac{5}{\max \{5553443\}}=\frac{5}{5}=1 \\
& \mathrm{R}_{6,3}=\frac{5}{\max \{5553443\}}=\frac{5}{5}=1 \\
& \mathrm{R}_{6,4}=\frac{3}{\max \{5553443\}}=\frac{3}{5}=0.6 \\
& \mathrm{R}_{6,5}=\frac{4}{\max \{5553443\}}=\frac{4}{5}=0.8 \\
& \mathrm{R}_{6,6}=\frac{4}{\max \{5553443\}}=\frac{4}{5}=0.8 \\
& \mathrm{R}_{6,7}=\frac{3}{\max \{5553443\}}=\frac{3}{5}=0.6
\end{aligned}
$$

Maka matriks R sebagai berikut :

$$
\mathrm{R}=\left(\begin{array}{cccccc}
0.6 & 0.6 & 0.4 & 0.6 & 1 & 1 \\
0.6 & 1 & 0.6 & 0.4 & 0.75 & 1 \\
0.6 & 1 & 0.4 & 0.4 & 1 & 1 \\
1 & 1 & 1 & 0.6 & 0.75 & 0.6 \\
1 & 0.6 & 0.8 & 1 & 1 & 0.8 \\
1 & 0.5 & 0.6 & 0.2 & 1 & 0.8 \\
0.6 & 1 & 0.8 & 0.8 & 1 & 0.6
\end{array}\right)
$$

Untuk mencari nilai dari masing-masing calon penerima bantuan dipakai rumus seperti berikut, maka nilai $\mathrm{V}_{\mathrm{i}}$ harus diketahui dengan rumus:

$$
\mathrm{V}_{\mathrm{i}}=\sum_{\mathrm{j}=1}^{\mathrm{n}} \mathrm{w}_{\mathrm{j}} \mathrm{r}_{\mathrm{ij}}
$$

Keterangan :

$\mathrm{Vi}=$ ranking untuk setiap alternatif

$\mathrm{wj}=$ nilai bobot dari setiap kriteria

rij = nilai rating kinerja ternormalisasi

Jadi :

$$
\begin{aligned}
& \mathrm{V} 1=0.6(4)+0.6(4)+0.4(4)+0.6(3)+1(2)+1(4) \\
& \mathrm{V} 1=14.2 \\
& \mathrm{~V} 2=0.6(4)+1(4)+0.6(4)+0.4(3)+0.75(2)+1(4) \\
& \mathrm{V} 2=15.5 \\
& \mathrm{~V} 3=0.6(4)+1(4)+0.4(4)+0.4(3)+1(2)+1(4) \\
& \mathrm{V} 3=15.2 \\
& \mathrm{~V} 4=1(4)+1(4)+1(4)+0.6(3)+0.75(2)+0.6(4) \\
& \text { V4 }=17,7 \\
& \text { V5 }=1(4)+0.6(4)+0.8(4)+1(3)+1(2)+0.8(4) \\
& \text { V5 }=17,8
\end{aligned}
$$




$$
\begin{aligned}
& \text { V6 }=1(4)+0.5(4)+0.6(4)+0.2(3)+1(2)+0.8(4) \\
& \text { V6 }=14,2 \\
& \text { V7 }=0.6(4)+1(4)+0.8(4)+0.8(3)+1(2)+0.6(4) \\
& \text { V7 }=16,4
\end{aligned}
$$

\subsection{Hasil}

Dari hasil perhitungan nilai $\mathrm{V}_{\mathrm{i}}$ dari setiap calon penerima bantuan maka dapat dibuat tabel penentuan ranking, seperti tabel berikut :

Tabel 12 Penentuan Ranking

\begin{tabular}{|c|l|c|c|}
\hline NO & \multicolumn{1}{|c|}{ Nama } & Ranking & Nilai \\
\hline 1 & Raden Josua Sihombing & 6 & 14,2 \\
\hline 2 & Fransiska Manullang & 4 & 15,5 \\
\hline 3 & Abidin Siregar & 5 & 15,2 \\
\hline 4 & Zulkifli Lumban Toruan & 2 & 17,7 \\
\hline 5 & Marudut Sinaga & 1 & 17,8 \\
\hline 6 & Martina Manullang & 7 & 14,2 \\
\hline 7 & Lestari Aritonang & 3 & 16,4 \\
\hline
\end{tabular}

Dari penentuan prioritas usulan penerima bantuan dengan menggunakan metode simple additive weighting maka yang layak menerima bantuan siswa miskin adalah Marudut Sinaga dan Zulkifli Lumban Toruan karena mereka memiliki nilai yang lebih tinggi sebesar 17,7.

\section{KESIMPULAN}

Dengan penerapan metode Simple Additive Weighting (SAW) menghasilkan nilai dari penentuan kriteria, pembobotan, rating kecocokan, normalisasi, dan perankingan sehingga menghasilkan nilai dari masing-masing kriteria dan setelah melakukan penghitungan maka didapatkan nama sisswa Marudut Sinaga dengan nilai sebesar 17,8 dan Zulkifli Lumban Toruan karena mereka memiliki nilai yang lebih tinggi sebesar 17,7 .

\section{DAFTAR PUSTAKA}

[1] Ratna Ningsih, "Bantuan Siswa Miskin, Sasaran, Kendala Dan Kenyataan Di Lapangan - Jabar Publisher,” 2018. [Online]. Available: https://jabarpublisher.co.id/2018/01/16/bantuan-siswa-miskin-sasaran-kendala-dan-kenyataan-lapangan/. [Accessed: 25-Apr-2020].

[2] B. Rahmat, "Dampak Bantuan Siswa Miskin (Bsm) Di Sekolah Dasar Negeri Gentan Kecamatan Ngaglik Kabupaten Sleman," J. Manaj. Pendidik. UNY, vol. 12, no. 2, p. 113684, 2016.

[3] T. Limbong et al., Sistem Pendukung Keputusan : Metode dan Implementasi. Medan: Yayasan Kita Menulis, 2020.

[4] S. Mahulae and T. Limbong, "Implementasi Metode Simple Additive Weighting dalam Penentuan Guru untuk diusulkan Sertifikasi," MEANS (Media Inf. Anal. dan Sist., vol. 4, no. 1, pp. 58-63, 2019.

[5] T. Limbong and R. Limbong, "IMPLEMENTASI METODE SIMPLE ADDITIVE WEIGHTING DALAM PEMILIHAN BIBIT UNTUK BUDIDAYA IKAN MAS," J. Tek. Inform. Kaputama, vol. 2, no. 1, pp. 115-122, 2018, doi: 10.13140/RG.2.2.10083.45609.

[6] D. M. Rajagukguk, "Implementasi Metode Simple Additive Weighting pada Sistem Pendukung Keputusan Penerima Beasiswa," Edu Komputika J., vol. 4, no. 1, pp. 55-55, 2017.

[7] Sugiyono, Metode Penelitian Kuantitatif, Kualitatif dan R\&D. Bandung: PT Alfabet, 2016.

[8] J. Simarmata, T. Limbong, M. Aritonang, and S. Sriadhi, "SISTEM PENDUKUNG KEPUTUSAN PEMILIHAN GURU BIDANG STUDI KOMPUTER MENGGUNAKAN METODE SIMPLE ADDITIVE WEIGHTING (SAW)," Comput. Eng. Sci. Syst. J., vol. 3 , no. 2, pp. 186-190, 2018. 